\title{
Contribution of Geomatics to the Delimitation of Protection Perimeters: Case of Agbo River in Agboville (South-East of Côte d'Ivoire)
}

\author{
Gabriel Etienne Ake ${ }^{*}$, Anowa Evrade Larissa Eba1, Louan Odile Bleㄹ, Aïchatou Adebayo1, \\ Jean Jaurès Assi' ${ }^{1}$, Mahaman Bachir Saley ${ }^{1,2}$, Jean Biemi' ${ }^{1}$ \\ ${ }^{1}$ Water and Environment Sciences and Technical Laboratory (WESTL), UFR of Earth Sciences and Mineral Resources, University \\ of Felix Houphouet-Boigny, Abidjan, Côte d'Ivoire \\ ${ }^{2}$ University Center for Research and Application in Remote Sensing (UCRARS), Abidjan, Côte d'Ivoire \\ Email: ^ak_gabe@yahoo.fr, ebaballiet@gmail.com, louanfr2000@yahoo.fr, adebayo.aichatou@gmail.com, asjeajau@gmail.com, \\ basaley@yahoo.fr, jbiemi@yahoo.fr
}

How to cite this paper: Ake, G.E., Eba, A.E.L., Ble, L.O., Adebayo, A., Assi, J.J., Saley, M.B. and Biemi, J. (2020) Contribution of Geomatics to the Delimitation of Protection Perimeters: Case of Agbo River in Agboville (South-East of Côte d'Ivoire). Journal of Environmental Protection, 11, 470-490. https://doi.org/10.4236/jep.2020.116028

Received: April 29, 2020

Accepted: June 19, 2020

Published: June 22, 2020

Copyright $\odot 2020$ by author(s) and Scientific Research Publishing Inc. This work is licensed under the Creative Commons Attribution International License (CC BY 4.0).

http://creativecommons.org/licenses/by/4.0/ cc) (i) Open Access

\begin{abstract}
The present study aims to delimit protection perimeters around the "Agbo" river in Agboville in order to reduce the risks of pollution of this water resource. The methodological approach consisted first all in assessing the vulnerability of the resource and then in determining the protection perimeters based on the vulnerability map and previous studies. Five parameters (slope, land use, soil type, annual runoff and drainage density) were used. These parameters were then weighted using the Saaty multicriteria analysis method. The vulnerability map reveals four classes (very low, low, medium and high) with a dominance of the low class (41.35\% of the area). Three protection perimeters were delineated (immediate, close and remote). The immediate protection perimeter is delimited at a distance of $200 \mathrm{~m}$ around the SODECI water intake on the "Agbo" river and covers the areas with a strong influence on the vulnerability to pollution of the river. The closer protection perimeter at a distance of $1000 \mathrm{~m}$, is represented by the zones with strong influence on the vulnerability of the resource and the direction of water flow in the watershed. Finally, the remote protection perimeter covers a large part of the catchment area with a surface area of $510.36 \mathrm{~km}^{2}$ and takes into account the zones that have an influence on the vulnerability to pollution of the resource. These delimited protection perimeters can serve as a guide for the management and protection of the water intake in Agboville as well as for land use planning in this area.
\end{abstract}

\section{Keywords}

Vulnerability, Protection of Perimeters, Multicriteria Analysis, Agboville, 


\section{Introduction}

In several regions of the world, water resources (surface and groundwater), mostly surface water, are increasingly threatened by pollution. One of the causes of the degradation of the quality of these surface waters would be related to the increasing amount of polluting discharges into the receiving environments without prior treatment [1]. So, they point out that land use related to agricultural, urban and industrial activities has contributed, over the last few decades, to increasing the potential for surface water contamination and, in some cases, to increasing the risk of contamination. In Côte d'Ivoire, most of the cities located on the crystalline basement have surface water as main source of drinking water supply [2]; this is the case of the city of Agboville. In this locality, the river "Agbo" which is the main source of drinking water supply for the populations is increasingly threatened by agricultural and domestic activities as revealed by N'go et al. [3]. This threat is reflected in its high load of organic and mineral matter, so that the current treatments of the Water Distribution Company in Côte d'Ivoire (WDCCI) are no longer able to purify the water properly [3].

To ensure efficient and sustainable management of the resource intended for supplying drinking water to the population, it is essential to protect it from various sources of pollution. In this sense, one of the alternatives offered to the scientific community is to proceed with the delimitation of protection perimeters around the said resource. In this way, it allows giving the authorities in charge of its management a working tool to better orient and regulate the activities that take place in its catchment area.

Indeed, as several European directives underline that, these drinking catchments must be provided with a protection perimeter in order to avoid pollution related to normal human activities and to reduce the risk of accidental pollution that could lead to water contamination and consequently to a health crisis.

In Côte d'Ivoire, they are prescribed by article 34 of the water code and its implementation decree $\mathrm{n}^{\circ} 2013-440$ of 13 June 2013 determines the legal regime of the perimeters for the protection of water resources, hydraulic installations and structures. However, the delimitation of these perimeters requires a meticulous study in the vicinity of the resource. GIS is a computerized solution for the delimitation of protection perimeters as shown by Garouani et Abdelaziz [1]. It allows a broad and especially digital knowledge of water resources and their protection [4].

In this context, the present study was undertaken with the purpose to delimit the protection perimeters around the "Agbo" river in the Upper Agneby watershed in Agboville for its sustainable management. It integrates into its approach the tools of geomatics in particular GIS coupled with the multi-criteria analysis of Saaty [5]. 


\section{Study Area Overview}

\section{Geographical Location}

Agneby watershed covers an area of $8495 \mathrm{~km}^{2}$ [6], and is located in a forest zone between latitudes $5^{\circ} 20 \mathrm{~N}$ and $6^{\circ} 55 \mathrm{~N}$, and between longitudes $3^{\circ} 45 \mathrm{~N}$ and $4^{\circ} 35 \mathrm{~W}$ (Figure 1). It is drained by the Agneby river which flows into the Ebrie lagoon near the Atlantic Ocean in South of Côte d'Ivoire [7].

The study was carried out at the water intake of the Water Distribution Company in Côte d'Ivoire (WDCCI) on the "Agbo" river in Agboville.

The average annual and monthly rainfall recorded respectively on the northern part of the Agneby basin from 1901 to 2002 varies between $108.39 \mathrm{~mm}$ and $116.61 \mathrm{~mm}$ and $15.66 \mathrm{~mm}$ and $284.85 \mathrm{~mm}$.

The vegetation of the basin consists of dense humid forest, cleared forest, swamp forest and very rarely savannah included [8].

As all of eastern Côte d'Ivoire, the upper Agneby basin is based on Precambrian formations, attached to the Birimian stage, which has undergone little metamorphism [9]. These are essentially arkosic shales found to the north around Bongouanou and to the south of Agboville.

We encounter in this zone ferralitic soils resulting from the alteration of shales or granites, with a zone of iron accumulation and induration (concretion and armouring) in the plateau and slope profiles. On the lower slopes, sandy and clayey accumulations of colluvial origin give very leached soils, with a clear tendency to hydromorphy at depth. Finally, in the thalwegs, typically hydromorphic sandy-clay soils are found [9].

On the whole, the relief is little accentuated, the Precambrian substratum having undergone slow erosion since the primary era. From downstream to upstream of the basin, the altitudes encountered are between 0 and $100 \mathrm{~m}$, and between 100 and $200 \mathrm{~m}$, respectively. Just to the extreme west of the upstream part of the basin, the extension of the Bongouanou hills is felt with altitudes between 200 and $300 \mathrm{~m}[10]$.

Agneby, the main river of the catchment area, is oriented roughly in a NorthSouth direction and receives many tributaries (Figure 2). Its length is $250 \mathrm{~km}$ [9].

The relatively steep relief of the hills to the North and West of Bongouanou favours runoff, which is rapidly concentrated in numerous streams flowing eastward. These streams all gather in a thalweg that runs from North to South along the edge of these hills to form "Agbô", the generic name of the main collector in the region [9].

Nearly $85 \%$ of the population have their socio-economic activities based on food crops (cassava, maize, yam, rainfed rice) and cash crops (sweet banana, coffee, cocoa, oil palm and rubber) [11]. The anthropic influence on the hydrographic network of the study area is very important due to the development of numerous water reservoirs on the Agneby river and its tributaries. The purpose of these various developments is to improve the living conditions of riparian 
populations, but they also result in a change in the watercourse regime. This may lead to more or less contamination of water resources [12].

\section{Material and Methods}

The setting up of a database made up of cartographic, satellite and climatic data was necessary to carry out this study.

\subsection{Material}

\subsubsection{Cartographic Data}

The cartographic data are made up of:

- geological sketch of Côte d'Ivoire (South-East sheet) at a scale of 1/500,000 made at SODEMI in 1972 and was used to make the geological map of the

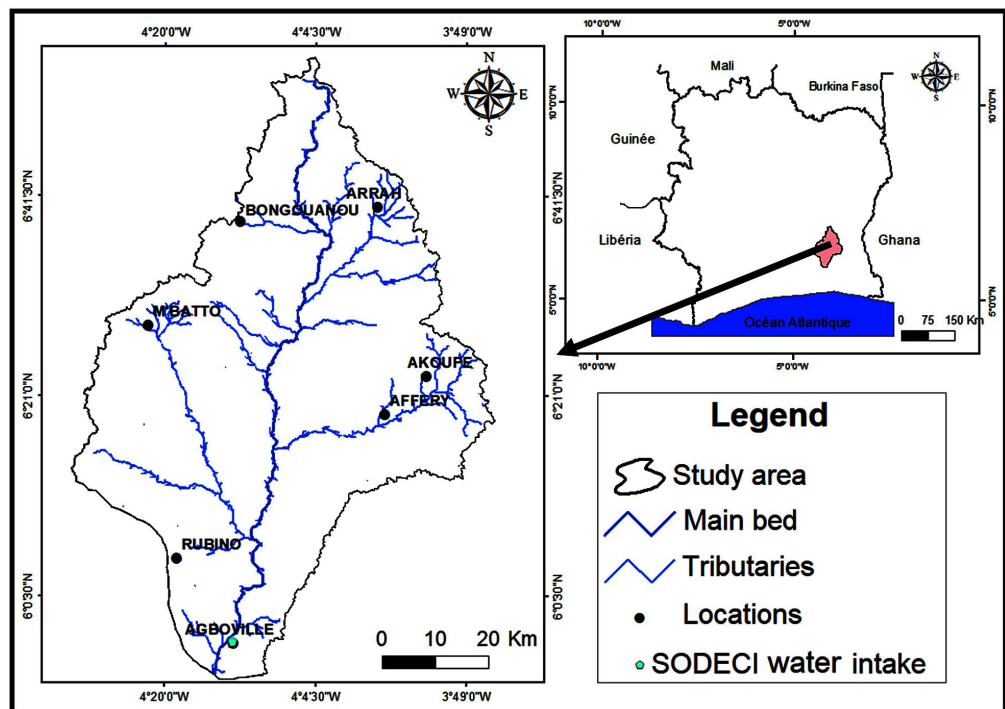

Figure 1. Geographical location of the upper Agneby watershed.

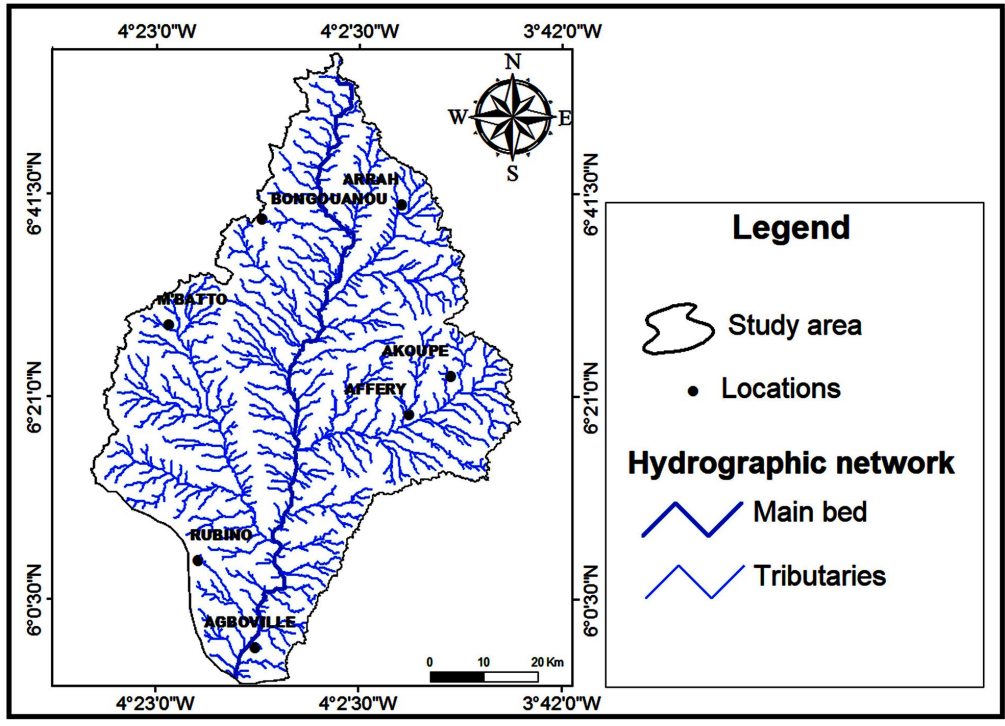

Figure 2. Map of the hydrographic network of the upper Agneby watershed. 
study area;

- pedological sketch of Côte d'Ivoire at a scale of 1/500,000 drawn up by the pedology laboratory of the ORSTOM centre in Adiopodoume [13] was used to produce the pedological map of the study area.

\subsubsection{Climatic Data}

They concern the average monthly rainfall data for the Agboville and Abidjan stations from 1901 to 2001 acquired from the Development and Operation, Airport, Aeronautical and Meteorological Society (DOAAMS) which were used to determine the annual rainfall.

\subsubsection{Satellite Data}

They are made up of:

- Shuttle Radar Topography Mission (SRTM) images with $30 \mathrm{~m}$ resolution and coordinates N05W005V3 and N06W005V3 of Côte d'Ivoire. They enabled the slopes and drainage density map of the study area to be drawn up.

- Sentinel images (2018 and 2019) in 10 m resolution. They were used to establish the land use map.

\subsection{Methods}

The approach used in this study, for the delimitation of protection perimeters, consist in combining remote sensing image processing techniques with the possibilities offered by GIS [1].

This method consists to produce a vulnerability map by which the map of protection perimeters is established. To make it, all the factors and combinations of factors that can contribute to the assessment of the vulnerability of the water resource are identified.

Since the study is carried out at a scale of hydrological unit, only factors identifiable at that scale are used, namely: land use, topographic slope, drainage density, soil types and rainfall quantity to assess runoff. Each of the required factors is then prioritized and weighted according to the importance of its role in the process of delineating protection perimeters. This methodological approach has been used by several authors in Côte d'Ivoire, namely Eba et al. [2] in Gagnoa; Anoh [14] in Taabo; Deh et al. [15] in Adzope; Ake et al. [16] in Aboisso and in other countries, namely Garouani et Abdelaziz [1] in Morocco (Hachef dam).

\section{Assessment of the Vulnerability to the Pollution of the Upper Agneby}

1) Mapping and reclassification of selected parameters

\section{a) Slope}

A study area mask was applied to the Côte d'Ivoire DEM to obtain the study area DEM. From this DEM, "Slope" parameter was realized using ArcGis "Slope" tool. The slope map (Figure 3 ) shows the existence of slopes ranging from $0 \%$ to $47 \%$. 


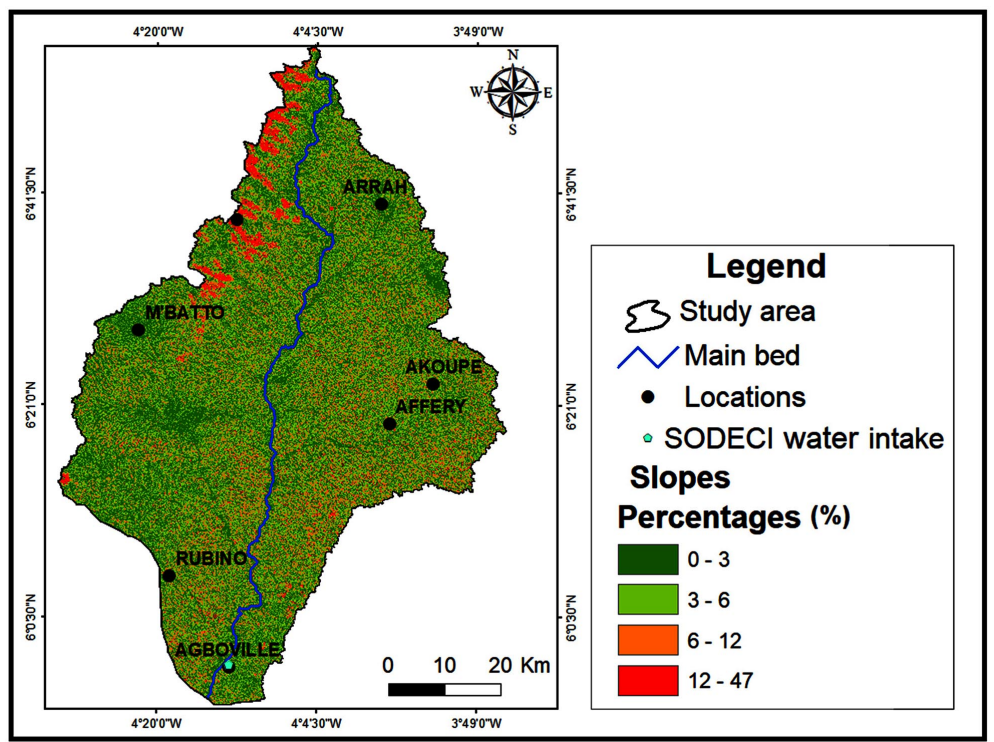

Figure 3. Slope map of the upper Agneby watershed.

\section{b) Soil type}

The soil map of the study area was obtained from the soil sketch of Côte d'Ivoire at a scale of $1 / 500,000$ [13].

The area has three main soil categories (Figure 4):

- typical ferralitic soils with high desaturation;

- slightly desaturated ferralitic soils;

- hydromorphic gley and pseudogley soils.

c) Runoff

It represents the share of rain that feeds the surface network [17]. The "annual runoff" parameter was determined by multiplying the runoff coefficient by the average annual rainfall for the region (Thornthwaite method). In this study, the $13 \%$ runoff coefficient determined by Soro [18] on the area of the Me river in South-Eastern Côte d'Ivoire was used as it has similar morphological and climatic characteristics to the study area.

The rainfall data used are those of five stations from 1901 to 2002:

1) average annual rainfall of the station in Bongouanou is $1488.10 \mathrm{~mm}$;

2) average annual rainfall of the station in Arrah is $1113.81 \mathrm{~mm}$;

3) average annual rainfall of the station in Agboville is $1488.10 \mathrm{~mm}$;

4) average annual rainfall of the station in Akoupe is $1413.10 \mathrm{~mm}$;

5) average annual rainfall of the station in M'batto is $1382.86 \mathrm{~mm}$.

The annual runoff is determined by the formula noted 1 :

$$
R=r \times P
$$

With:

$R=$ annual runoff $(\mathrm{mm})$;

$r=$ runoff coefficient (\%);

$P=$ annual rainfall $(\mathrm{mm})$.

The annual runoff values were spatialized over the entire upper Agneby watershed (Figure 5). 


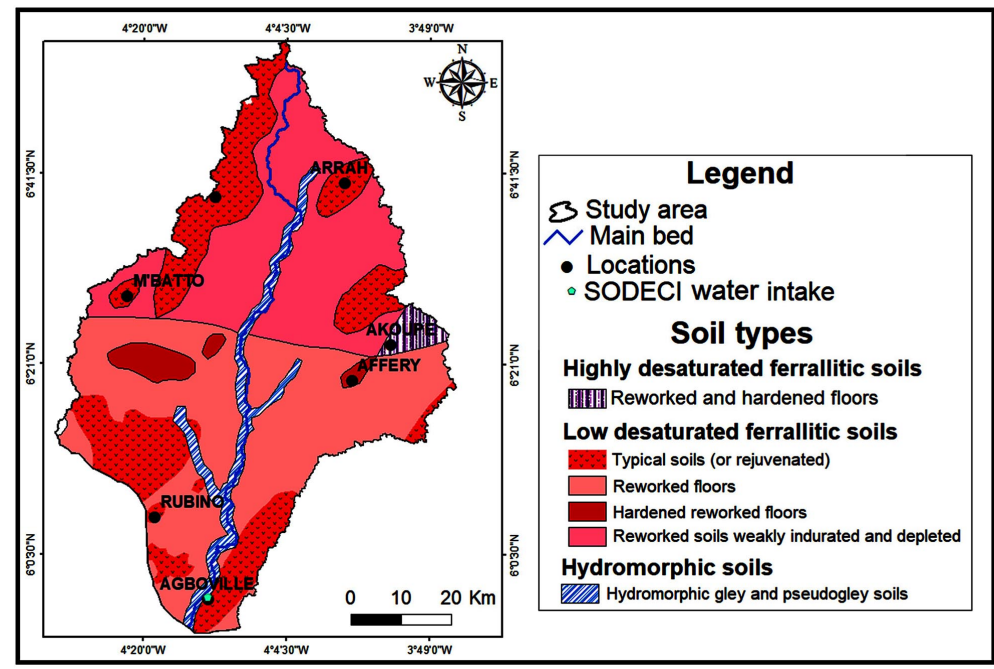

Figure 4. Soil type map of the upper Agneby watershed.

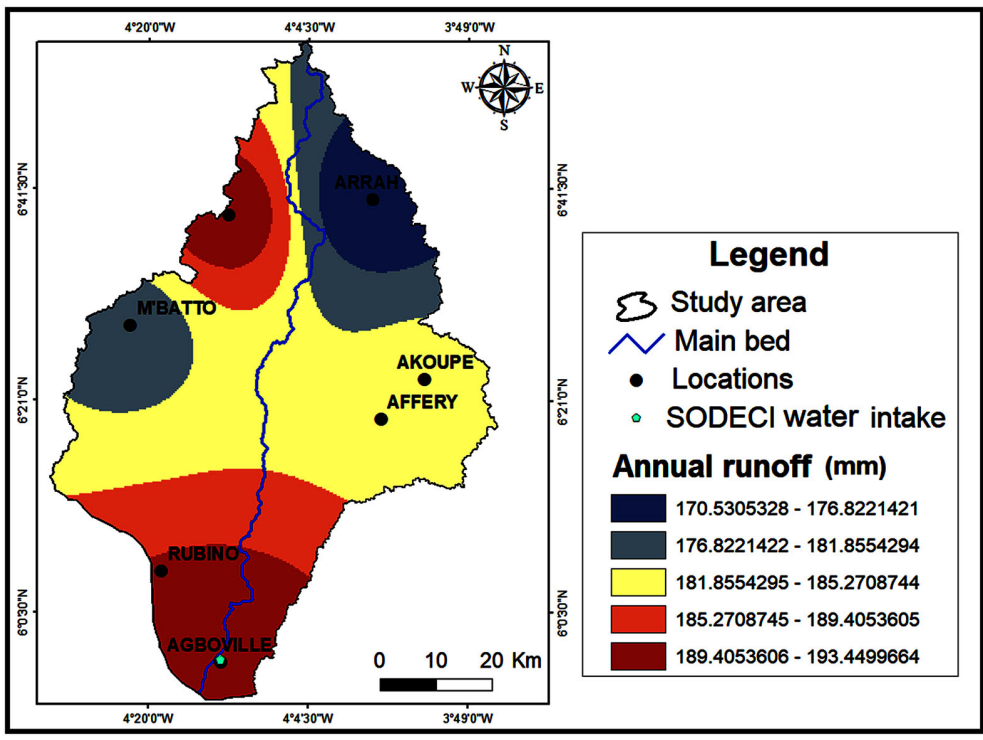

Figure 5. Spatial distribution of annual runoff of the upper Agneby watershed.

\section{d) Drainage density}

The drainage density map of the area hydrographic network was obtained from the hydrographic network through the "line-density" tool of the ArcGis software.

Density values range from 0 to $96.84 \mathrm{~km} / \mathrm{km}^{2}$. The density map (Figure 6) shows a high density around the rivers and at the tributary crossings. Density decreases with distance from individual tributaries.

\section{e) Land use}

Land use map is a very important parameter in land use and management. The importance of this factor lies in the fact that it shows most of the anthropogenic activities carried out, highlighting the surface conditions in the study area. Given the potential and the agricultural vocation of the upper Agneby, this parameter is likely to inform any development decision in the area and to draw up 
the main guidelines for regional development. This parameter was obtained by processing Sentinel satellite images through the "Impact Tool" module. It made it possible to make radiometric and atmospheric corrections with the unique use of multispectral bands. The extraction of the study area was done after the mosaic. Thereafter, the image processing was done by making a coloured composition (Sentinel bands 7-8-10) in order to better discriminate the geographical objects between them. Training sites representing all types of land use were selected on the coloured composite to run the supervised classification. These sites are selected based on accessibility and spatial distribution. This supervised classification made it possible to discriminate between five land use classes (Figure 7): water, degraded forest, industrial crops, habitats and bare soil, and crop and fallow mosaic, which were validated by a field mission (8 and 9 October 2019).

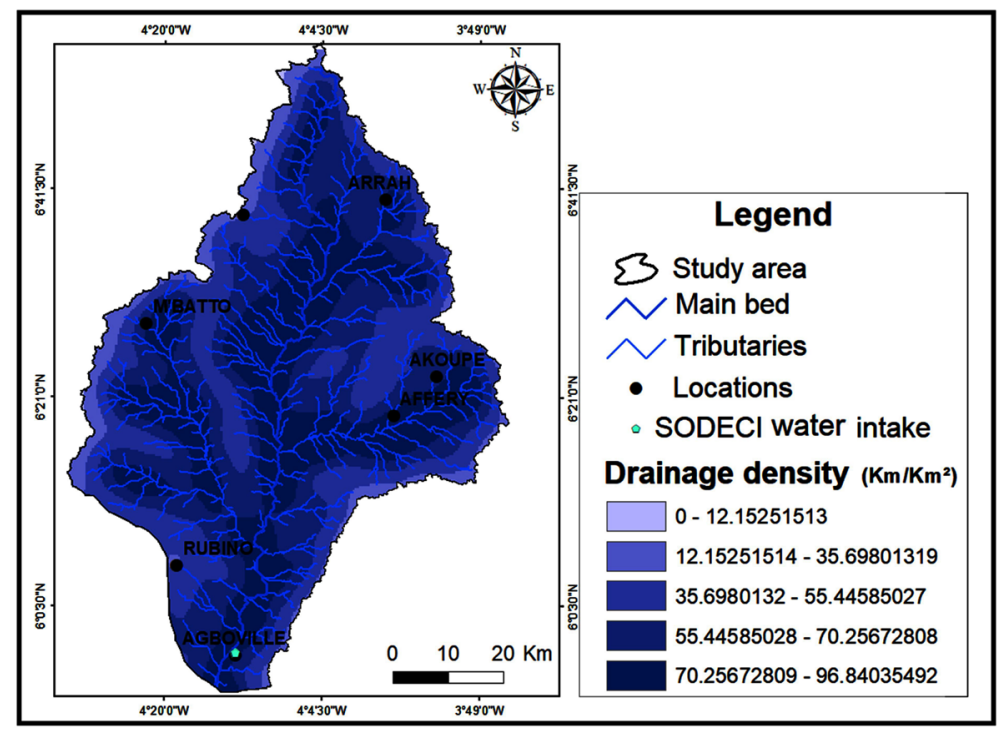

Figure 6. Drainage density map of the upper Agneby watershed.

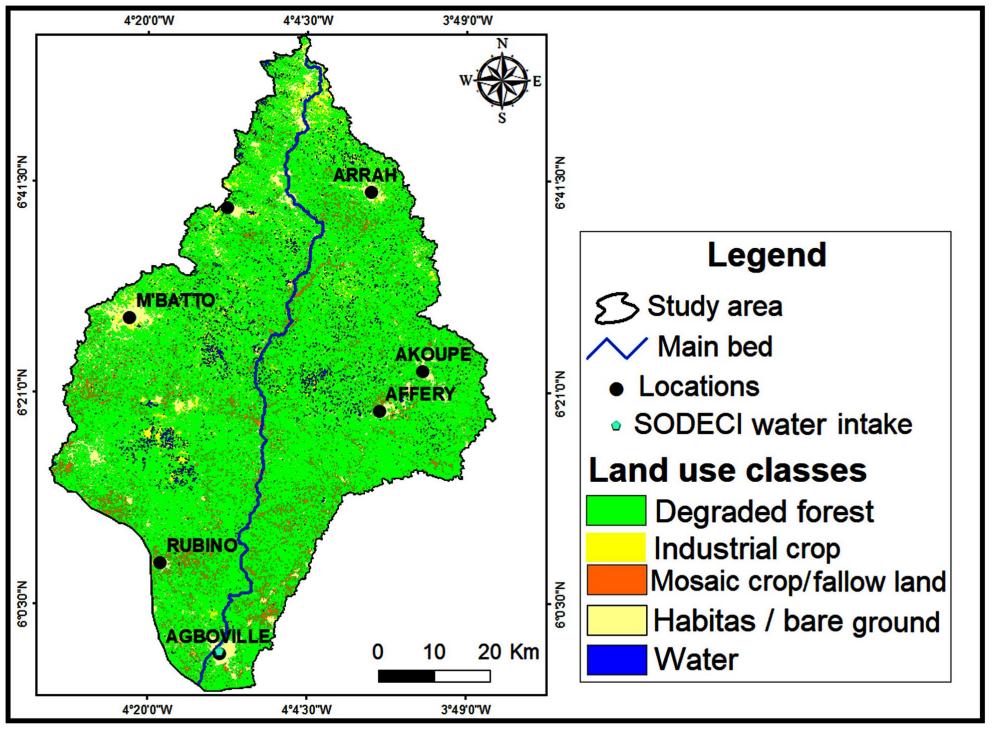

Figure 7. Land use map of the upper Agneby watershed. 


\section{2) Parameter weighting by Saaty multi-criteria analysis}

a) Elaboration of the square matrix

The method of Saaty [19], used by Eba et al. [2] Deh et al. [15] Ake et al. [16] El Morjani [20] has been exploited. It is a pairwise comparison method using the Analytical Hierarchy Process (AHP). It consists of comparing the relative importance of all selected parameters taken in pairs to configure a reciprocal square matrix. This comparison is done on the basis of a numerical scale of 9 levels [19] of pairwise comparison. When two parameters have the same importance in the studied phenomenon, the scale of Saaty gives them the value of " 1 ". However, if one parameter is more important than the other, then it takes a higher value between 1 and 10 and the other, the inverse of this value.

This method produces standardised weighting coefficients of which the sum is equal to " 1 ". The matrix resulting from the pairwise comparison of the different factors is summarised in Table 1.

This square matrix from the hierarchy was used to make the combinations for weight determination, with $\sum a_{i}$ equal to the sum of the parameters per column.

\section{b) Determination of the different weighting coefficients}

The weight of one element expresses its importance relative to another [19]. It corresponds to the intensity of its impact in the study of the vulnerability of the water resource. The determination of these weights is equivalent to calculate the weighting coefficient for each element. This coefficient is calculated using the formula (2):

$$
C_{p}=\frac{V_{p}}{\sum V_{p}}
$$

$V_{p}$ corresponds to the eigen vector of each element compared. It is determined as follows:

$$
V_{p}=\sqrt[k]{w_{1} \times \cdots \times w_{k}}
$$

Before determining the various weighting coefficients, it is checked that the basic matrix established (Table 2) is consistent. For this purpose, the Coherence Ratio $(C R)$ is calculated, which serves as a reference for judging the coherence of the matrix.

Table 1. Matrix resulting from the comparison of the different parameters (Original matrix).

\begin{tabular}{cccccc}
\hline & $P$ & $\boldsymbol{O S}$ & $\boldsymbol{S}$ & $\boldsymbol{R}$ & $\boldsymbol{D}$ \\
\hline $\boldsymbol{P}$ & 1 & 3 & 4 & 5 & 7 \\
$\boldsymbol{S}$ & $1 / 3$ & 1 & 3 & 4 & 4 \\
$\boldsymbol{R}$ & $1 / 4$ & $1 / 3$ & 1 & 2 & 3 \\
$\boldsymbol{D}$ & $1 / 5$ & $1 / 4$ & $1 / 2$ & 1 & 1 \\
Total $\sum a_{i}$ & $1 / 7$ & $1 / 5$ & $1 / 4$ & $1 / 3$ & 20 \\
\hline
\end{tabular}


Table 2. Random index ( $R I)$ values of a matrix of the same size [5].

\begin{tabular}{ccccccccccc}
\hline Number of variables & 2 & 3 & 4 & 5 & 6 & 7 & 8 & 9 & 10 & 11 \\
\hline$R I$ & 0 & 0.58 & 0.9 & 1.12 & 1.24 & 1.32 & 1.41 & 1.45 & 1.49 & 1.51 \\
\hline
\end{tabular}

If the value of the ratio is less than $10 \%$ then the judgements are consistent; otherwise they may require some revisions.

The ratio is equal to the ratio of the coherence index $(C D)$ to the random index $(R I)$ and is given by the following equation:

$$
\begin{gathered}
C R=\frac{C I}{R I} \\
\text { With } C I=\frac{\lambda_{\max }-\text { number of elements compared }}{\text { number of elements compared }-1}
\end{gathered}
$$

$C I$ is the Coherence Index $R I$, the Random Index and $\lambda_{\max }$, the maximum eigenvalue.

- If $C R \leq 10$, then the matrix is said consistent.

- If $C R>10 \%$ then the matrix is inconsistent and will need to be revised.

The calculation of $\lambda_{\max }$ is explained below. In addition, the values of the random index are given as a function of the number of parameters compared and are recorded in Table 2.

The value of $R I$ is " 1.12 " because five parameters were combined to assess the vulnerability of the "Agbo" river to pollution. Knowing the Random Index $(R I)$, one should try to determine the Coherence Index $(C D)$.

The steps are as follows:

- Step 1: normalize the original matrix by dividing each element of a column by the sum of that column;

- Step 2: make the average of each row to determine the priority vector [ $C]$;

- Step 3: multiply each column of the matrix by its corresponding priority vector to determine the overall priority $[D]$;

- Step 4: divide each global priority by its corresponding priority vector to determine the rational priority $[E]$;

- Step 5: determine the average of the rational priorities $\left(\lambda_{\max }\right)$;

$$
\lambda_{\max }=\frac{[E]}{k}
$$

- Step 6: calculate the Coherence Index $(C D)$ :

$$
C I=\frac{\lambda_{\max }-k}{k-1}
$$

Finally, the Coherence Ratio is deduced by the following formula:

$$
R C=\frac{I C}{I a}
$$

Calculation of Coherence Ratio $(C R)$ of the study:

$\checkmark$ Calculation of the average of the rational priorities $\left(\lambda_{\max }\right)$; 


$$
\begin{aligned}
& \lambda_{\text {max }}=\frac{26.10}{5} \text { because } E=26.10 \text { and } k=5 ; \\
& \lambda_{\text {max }}=5.22 . \\
& \checkmark \text { Calculation of the Coherence Index }(C D) ;
\end{aligned}
$$

$$
C I=\frac{5.22-5}{5-1} ; C I=0.055 \text {. }
$$

$\checkmark$ Calculation of the Coherence Ratio;

$C R=\frac{0.055}{1.12} ; C R=0.05$ represents $5 \%$ so $C R<10 \%$. It is deduced that the judgements are consistent.

Table 3 and Table 4 bring together the results obtained from the various calculations.

Table 5 summarizes the classes, ratings and weights assigned to the different parameters in the assessment of the pollution vulnerability of the "Agbo" river.

c) Determination of the areas influencing the vulnerability to pollution of the river "Agbo" in Agboville

It consisted in determining the pollution vulnerability index map of the Bia in Aboisso by combining the different layers in a GIS. The approach chosen was the operational approach of the single synthesis criterion [21]. The calculation of the vulnerability index is done by the following Equation (9):

$$
I v=(0.47 \times P)+(0.23 \times O S)+(0.17 \times S)+(0.09 \times R)+(0.04 \times D)
$$

For each parameter, the weight $\left(C_{p}\right)$ is multiplied by the different corresponding scores. This calculation is performed with the "Raster Calculator" tool of the "Map Algebra" submodule of the Arcgis software. We obtain index intervals to which vulnerability classes are assigned.

The determination of index intervals is based on the intrinsic vulnerability method developed in the work [22]. It allows the conversion of vulnerability indices into percentages in order to better understand the expression of the degree vulnerability classification. The indices are divided into four vulnerability classes ranging from "very low" to "high" (Table 6). The degree of vulnerability increases with the index.

Table 3. Original matrix normalized.

\begin{tabular}{ccccccc}
\hline & $P$ & OS & $S$ & $\boldsymbol{R}$ & $\boldsymbol{D}$ & Row total \\
\hline $\boldsymbol{P}$ & 0.52 & 0.63 & 0.46 & 0.41 & 0.35 & 2.37 \\
$\boldsymbol{S}$ & 0.17 & 0.21 & 0.34 & 0.32 & 0.25 & 1.29 \\
$\boldsymbol{S}$ & 0.13 & 0.07 & 0.11 & 0.16 & 0.2 & 0.67 \\
$\boldsymbol{D}$ & 0.10 & 0.05 & 0.06 & 0.08 & 0.15 & 0.44 \\
Column total & 0.08 & 0.04 & 0.03 & 0.03 & 0.05 & 0.23 \\
\hline
\end{tabular}


Table 4. Weight of the different parameters selected.

\begin{tabular}{cc}
\hline Parameters selected & Weight \\
\hline Slope $(P)$ & 0.47 \\
Land use $(O S)$ & 0.23 \\
Soil type $(S)$ & 0.17 \\
Annual runoff $(R)$ & 0.09 \\
Drainage density $(D)$ & 0.04 \\
\hline
\end{tabular}

Table 5. Summary of the values assigned to the various parameters.

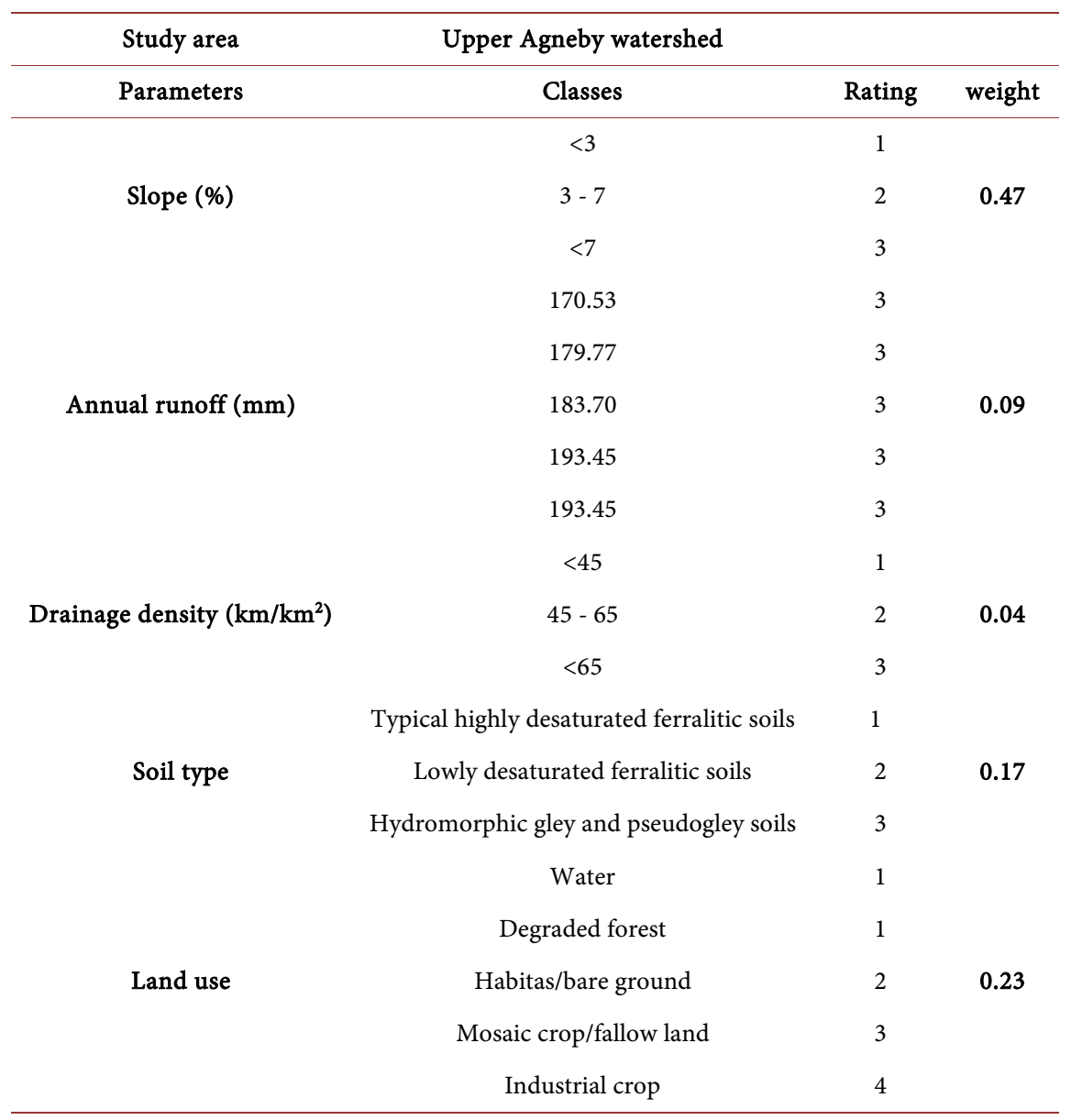

Table 6. Index and degree of vulnerability ([22], modified).

\begin{tabular}{ccc}
\hline Index of vulnerability & Degree of vulnerability \\
\hline $0 \%-30 \%$ & Very low \\
$31 \%-50 \%$ & Low \\
$51 \%-70 \%$ & Medium & High \\
$70 \%-100 \%$ & & \\
\hline & $I V(\%)=\frac{I V-I v_{\min }}{I v_{\text {max }}-I v_{\text {min }}} \times 100$ & \\
\hline 481 & & Journal of Environmental Protection
\end{tabular}


with:

$I V_{\text {min }}:$ Minimum vulnerability index; $I V_{\max }$ : Maximum vulnerability index.

\section{3) Determination of protection perimeters}

The protection perimeters (IPP, CPP and RPP) are determined from the pollution vulnerability map of the "Agbo" river. In addition, their delimitation was based on previous work and national legislation in force.

\section{a) Immediate Protection Perimeter (IPP)}

In general, the Immediate Protective Perimeter (IPP) is the immediate area around the intake. In the case of this study, the Immediate Protection Perimeter (IPP) was determined taking into account the most vulnerable areas adjacent or close to the water resource. The delimitation of this protection perimeter was carried out using the "Buffer" tool of the ArcGis "Arctoolbox" module.

\section{b) Closer Protection Perimeter (CPP)}

The CPP must maintain the quality of the water as it approaches the intake. The longitudinal extension of this perimeter must also provide a response time for the operator in the case of accidental pollution and its lateral extension must make it possible to limit runoff and reduce or eliminate the risks of pollution linked to activities on the slopes of the basin of the water body [23]. The methodological approach for its determination is used by several authors like Garouani et Abdelaziz [1] Eba et al. [2] Deh et al. [15] Ake et al. [16] Anoh et al. [24]. It consists in taking into account vulnerable areas, the direction of water flow and the slope. The "Buffer" tool and digitization have made it possible to carry out this delimitation. It makes it possible to determine a buffer zone around the resource to be protected [16].

c) Remote Protection Perimeter (RPP)

It corresponds to a complementary zone of the close protection perimeter. According to Eba et al. [2], this zone is connected to the outside of the close protection perimeter (CPP) and includes part or all of the recharge area of the catchment area, depending on whether point or non-point pollution is to be controlled.

\section{Results and Discussion}

\subsection{Map of Vulnerability to Pollution of the River "Agbo" in Agboville and Delimitation of the Different Protection Perimeters}

Figure 8 shows the values of the vulnerability indices. They range from 1.22 to 3.32. The highest values $(2.43-3.32)$ are located upstream in the watershed and around the Agneby stream.

The pollution vulnerability map of the "Agbo" river derived from the index map shows four degrees of vulnerability (Figure 9) namely: very low, low, medium and high with a dominance of the low class. Analysis by class allows us to say that the very low class occupies $34.60 \%$ of the study area, but is more represented in the western part of the watershed. This class is characterized by low slopes 
and degraded forests. Runoff in these areas is also negligible. This area is characterized by low drainage density.

Next, the low class occupies $41.35 \%$ of the study area. It is the dominant class because it is spread over the entire study area. Indeed, these areas are characterized by degraded forests, cultivated areas but left to rest (cultivation/fallow). This class is also characterized by average slopes.

Then there is the middle class, which covers $21.44 \%$ of the study area. It is found in cultivated areas. It is characterized by steep slopes and high drainage density.

Finally, the high class occupies $2.71 \%$ of the study area and is spread throughout the study area but is more represented upstream of the basin. This class takes into account cultivated and steeply sloping areas. In these areas, there are strong agricultural activities (cocoa, coffee, oil palm, etc.) that use agricultural inputs (fertilizers and phytosanitary products), as observed during our field visit.

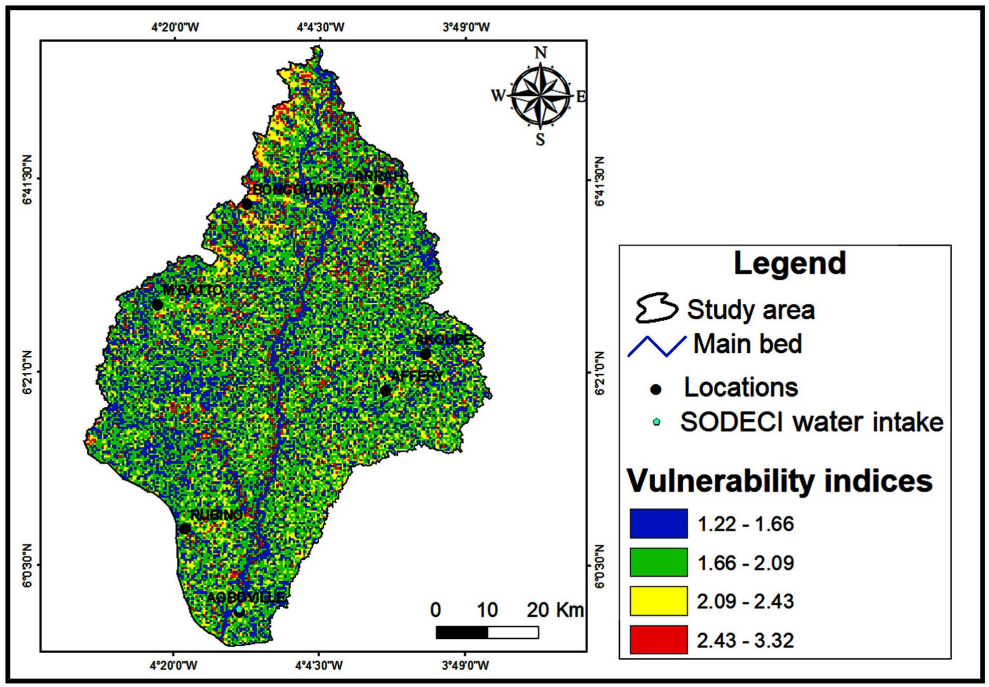

Figure 8. Map of vulnerability indices to pollution of the "Agbo" river.

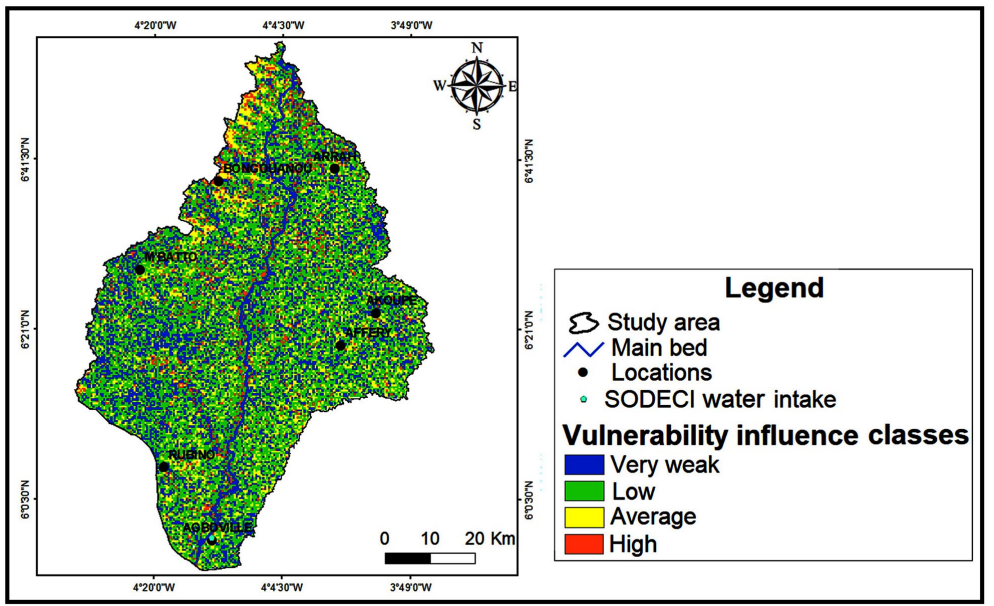

Figure 9. Pollution vulnerability map of the "Agbo" river. 


\section{Delimitation of Protection Perimeters}

Taking into account the map of the areas having an influence on the vulnerability to pollution of the river "Agbo" in Agboville, the map of the different protection perimeters (Figure 10) was drawn up.

It presents three zones of protection perimeters: immediate, close and remote.

$>$ Immediate Protection Perimeter

The immediate protective perimeter (Zone I) has been delimited at a radius of $200 \mathrm{~m}$ around the Agbo river in Agboville. It has an area of $4.82 \mathrm{~km}^{2}$. In addition, this zone takes into account areas with strong influences on the vulnerability to pollution of the river "Agbo". In this zone every activity should be prohibited except maintenance operations of the installations. It must therefore allow an effective protection of the reservoir and its water intake against so-called point source pollution. It allows to prevent the deterioration of the installations and the discharge of any type of pollutants or near the source.

Closer Protection Perimeter

The closer protection perimeter (Zone II) has been delimited at a radius of $1000 \mathrm{~m}$ from the limits of Zone I, taking into account the direction of water flow in the basin and the areas having an influence on the river "Agbo" and has an area of $32.59 \mathrm{~km}^{2}$.

It is an area in which some self-purification is possible and is also intended to preserve the captured water from degradation due to point or non-point pollution. Within this zone, any activity likely to affect the quality of the water resource should be prohibited or subject to special requirements.

$>$ Remote Protection Perimeter

This perimeter (Zone III) is a complementary zone to Zone II. It takes into account the catchment area of the river "Agbo", depending on whether point, diffuse or accidental pollution is to be controlled. In this case, it largely covers the entire surface of the basin located upstream and on the sides of the reservoir with a surface area of $510.36 \mathrm{~km}^{2}$.

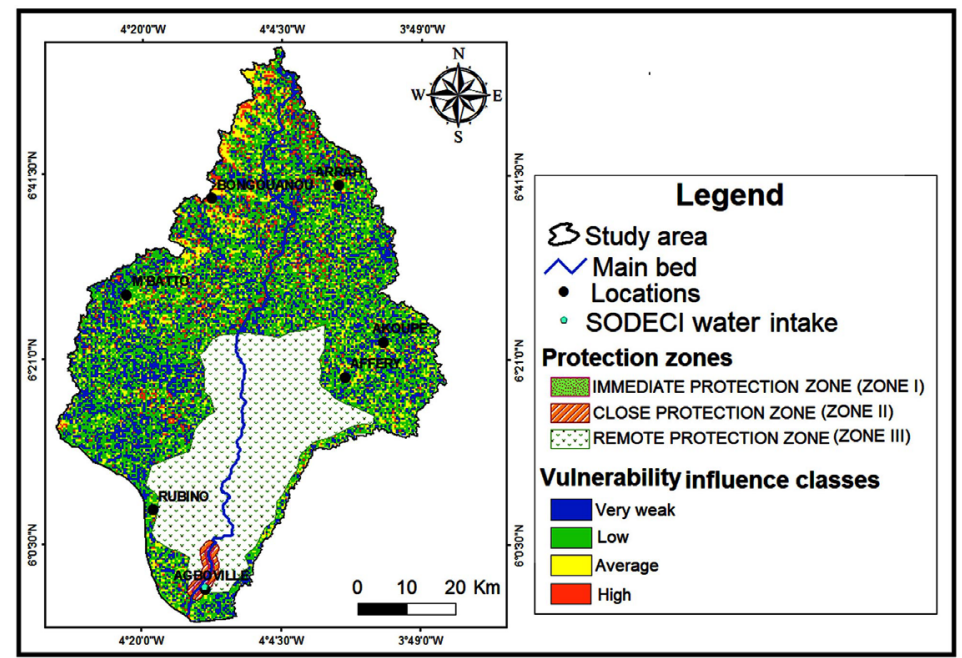

Figure 10. Map of the protection perimeters around the SODECI water intake on the "Agbo" river. 


\subsection{Discussion}

The GIS made it possible to produce the pollution vulnerability map of the river "Agbo" by ensuring the synthesis of the parameters taken into account through a multi-criteria analysis of Saaty. Five parameters were taken into account in assessing of the pollution vulnerability of this resource (land use, soil types, drainage density, annual runoff and slope). The determining parameter in this vulnerability mapping is the slope followed by land use as shown by Eba et al. [2] Ake et al. [16]. The mapping of vulnerability to pollution in the Agneby highlighted four classes of vulnerability (very low, low, medium and high). These classes are identical to those revealed by Anoh [14] using a GIS. Similar studies carried out by Deh et al. [15] Ake et al. [16] Eba et al. [17] Macary et al. [25] revealed five vulnerability classes (very low, low, medium, high and very high). In addition, Schoen et al. [26] determined three (low, medium and high) using calculation methods.

For Eba et al. [2], the vulnerability classes may vary from one study to another and from one region to another because they depend on the class boundaries and the scores initially assigned to these classes by the operator and also on the sensitivity of the operator.

The vulnerability index values obtained range from 1.22 to 3.32 , with the highest values being upstream and indicating high vulnerability at these locations.

In addition, the difficulty in producing a pollution vulnerability map using a GIS generally lies in the number and quality of the parameters to be taken into account. The reliability (often questionable data quality) and the very limited number of data often do not allow a good spatial assessment of the criteria. In this study, annual runoff was spatialised using five rainfall stations, unlike the work of Eba et al. [2] Deh et al. [15] Ake et al. [16] where runoff was considered as point data. A difficulty was encountered in weighting the parameters in the application of the multi-criteria analysis since the values assigned are subjective. Indeed, according to Eba et al. [2] Anoh et al. [24] Kpan [27], the subjectivity of the weights and ratings assigned to the parameters is a limiting factor. Moreover, the values assigned to the parameters sometimes tend to over- or underestimate the degree of vulnerability of the water resource. In spite these difficulties listed in the pollution vulnerability map, the vulnerability map produced remains reliable. It is of paramount importance in land use planning, management and protection of water resources and can serve as a decision-making tool for managers and authorities in Agboville.

The delimitation of the protection perimeters around the "Agbo" river in Agboville required prior knowledge of the areas having an influence on the vulnerability to pollution of the "Agbo" river. Three protection perimeters were delimited (IPP, CPP, RPP). The Immediate Protection Perimeter (IPP) was delimited at a radius of $200 \mathrm{~m}$ around the river "Agbo" and covers an area of 4.82 $\mathrm{km}^{2}$. 
It is intended to prohibit access to the sampling point and treatment facilities and to protect them from malicious acts. Some authors, such as Eba et al. [2] Anoh [14] Kpan [27] have limited the IPP to a radius of $200 \mathrm{~m}$ (Lake Taabo), $100 \mathrm{~m}$ (Gagnoa reservoir) and $450 \mathrm{~m}$ (Lake Adzope) respectively.

According to Bibeau et Breune [28], it must be delimited within an area of 150 to $300 \mathrm{~m}$ from the natural high-water line of the river. This limit is not exhaustive, it can be determined according to the state of the watercourse, its size and also the activities carried out in its environment Eba et al. [2].

According to Carre [23], the size of this area must allow for appropriate intervention in the event of an accident related to pollution of the water source. Within this zone, apart from maintenance and treatment activities, all activities that could deteriorate water quality are prohibited [23]. However, during the field visit, some anthropogenic activities were identified as contributing to the deterioration of water quality, notably the presence of a household garbage dump at the entrance to the site and the existence of habitats in the immediate vicinity of the intake. Finally, the quasi-permanent presence of aquatic plants on the watercourse testifies to the transport of nutrients from upstream activities that contribute to the eutrophication of the resource. The greenish colour of this water indicates the sources of pollution of the resource (Figure 11).

The closer protection perimeter was delimited taking into account the direction of water flow in the sub-basin. This zone is at a radius of $1000 \mathrm{~m}$ and covers an area of $32.59 \mathrm{~km}^{2}$. This Zone II was delimited at a distance of $1000 \mathrm{~m}$ in the works of Eba et al. [2] Deh et al. [15] Ake et al. [16]. According to Eba et al. [2], at this distance, it is possible that dissolved pollution directed towards the impoundment could be intercepted or trapped by the presence of adapted vegetation.

For Garouani et Abdelaziz [1], the zone II is delimited to adjacent land with a slope greater than 3 degrees, but without the extent of this strip exceeding one kilometer in width. The Meeb [29] recommends a close protection perimeter of between $100 \mathrm{~m}$ and $1 \mathrm{~km}$. For Carre [23], the width of this zone depends on the slope, banks and ground cover.

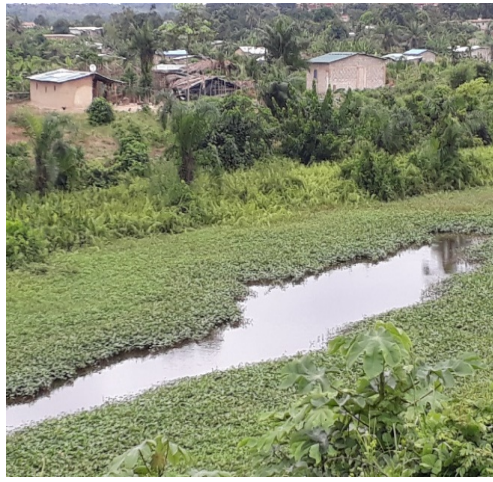

(a) Entrance to the intake station

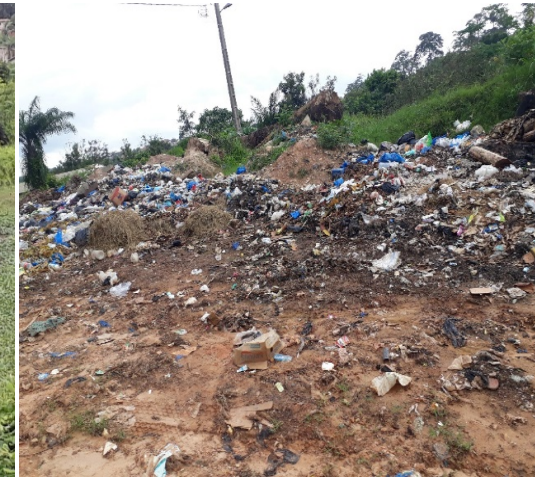

(b) Interior of the intake station

Figure 11. Dumping of household waste near the water intake (a) and eutrophication of the resource due to the presence of organic matter (b). 
According to Eba et al. [2], it all depends on the extent of the water source and the basin, the activities carried out within the basin that are likely to influence the vulnerability of the water source and the assessment of the executor. Finally, the remote protection perimeter (Zone III) has been delimited taking into account areas vulnerable to river pollution. It covers an area of $510.36 \mathrm{~km}^{2}$.

It must ensure the protection of waters against extensive deterioration, especially persistent pollution or hard to be eliminated as well as chemical or radioactive pollution [30]. It is an area where easements are non-binding, as it is optional, but can be justified when certain activities cause significant pollution [2].

For Garouani et Abdelaziz [1], it encompasses land with slopes of less than 3 degrees and the extent of this zone can increase or decrease by involving the other parameters and/or by adjustments according to cadastral (communes or parcels) and geographical (watercourses, communication routes) boundaries. Other authors extend this zone over the whole basin containing the water source (reservoir, lakes, river...). This is the case of Anoh [14] Ake et al. [16] Meeb [29]. This perimeter is not intended to lead to the creation of easements, but to alert the public more broadly to the need to preserve the quality of surface water intended for consumption Eba et al. [2]. Although the various protection perimeters have been delineated, it is nevertheless interesting to list some difficulties. Difficulties lie in the authors' assessment of the distance of protection perimeters. Indeed, the boundaries of the zones vary from one author to another.

In spite of all these difficulties, the protection perimeters are appreciable and can serve as a guide for the management and protection of the "Agbo" river in Agboville as well as in the planning of the territory in this zone in view of its strategic and determining importance.

\section{Conclusions}

The delimitation of the protection perimeters of the upper Agneby in Agboville watershed was carried out after an assessment prior to the vulnerability of this water resource to pollution through the vulnerability map. This map shows four classes of vulnerability: very low (34.60\%), low (41.35\%), medium (21.34\%), high (2.71\%). The map of vulnerability to pollution of the Agneby in Agboville is dominated by the very low and low classes, which together represent about $75.95 \%$ of the area studied.

Three protection perimeters have been delimited in this study in particular: the Immediate Protection Perimeter or Zone I; it covers an area of $4.82 \mathrm{~km}^{2}$ and has a radius of $200 \mathrm{~m}$ around the bank of the river "Agbo". The Close Protection Perimeter or Zone II, with a width of $1000 \mathrm{~m}$ was delimited from the limits of Zone I and covers an area of $39.59 \mathrm{~km}^{2}$.

Finally, the Remote Protection Perimeter or Zone III, covers an area of 510.36 $\mathrm{km}^{2}$. This zone covers a large part of the catchment area where the zones have a strong influence on water resources. This map of the perimeters is a decision- 
making tool for land use planning, management and protection of water resources in the upper Agneby catchment area.

\section{Conflicts of Interest}

The authors declare no conflicts of interest regarding the publication of this paper.

\section{References}

[1] Garouani, A. and Abdelaziz, M. (2006) Delimitation of the Protection Zones around the Reservoir of the Hachef Dam (Morocco) by Remote Sensing and GIS. Water Science Journal, 19, 1-10.

[2] Eba, A.E.L., Kouame, K.J., Jourda, J.P., Saley, M.B., Ake, G.E., Deh, S.K. and Anoh, K.A. (2013) Demarcation of Surface Water Protection Perimeters by Using GIS: Case of Gagnoa Reservoir in West Central of Côte d'Ivoire. International Journal of Scientific \& Engineering Research, 4, 1311-1320.

[3] N'go, Y.A., Gone, D.L., Savane, I. and Goble, M.M. (2005) Groundwater Potential of Cracked Aquifers in the Agboville Region (South-West of Côte d'Ivoire): Hydroclimatic and Physical Characterization. Afrique Science, 1, 127-144. https://doi.org/10.4314/afsci.v1i1.35401

[4] Koffi, K.J.P., N'go, Y.A., Yeo, K.M., Kone, D. and Savane, I. (2014) Determination of the Protection Perimeters of the Aghien Lagoon by Calculating the Time of Transfer of Water to the Lagoon. Larhyss Journal, 19, 19-35.

[5] Saaty, T.L. (1980) The Analytic Hierarchy Process: Planning, Priority Setting, Resource Allocation. McGraw-Hill, New York, 19 p.

[6] Goula, B.T.A., Kouadio, Z.A., Kouakou, K.E., N'go, Y.A., N'doume, C. and Savane, I. (2009) Simulation of the Hydrological Behavior of the Agneby Watershed in Côte d'Ivoire. Ivory Science Technology Review, 13, 91-113.

[7] Kamagate, B., Dao, A., Noufe, D., Yao, K.L., Fadika, V., Gone, D.L. and Savane, I. (2017) Contribution of the gr4j Model to the Hydrological Modeling of the Agneby Watershed in the South East of Côte d'Ivoire. Larhyss Journal, 29, 187-208.

[8] Avenard, J.M. (1971) Aspect of Geomorphology in the Natural Environment of Côte d'Ivoire. ORSTOM Memory, No. 50, Paris, 67 p.

[9] Girard, G., Sircoulon, J. and Touchebeuf, P. (1971) The Natural Environment of Côte d'Ivoire, Hydrology. ORSTOM Memories, Paris, No. 50, 359 p.

[10] ONEP (2017) Strengthening of the Drinking Water Supply in the Urban Centers of Agboville. National Office of Drinking Water, Scientific Report, 170 p.

[11] MINAGRA (2001) Ministry of Agriculture and Animal Resources, Directorate Statistics, Documentation and Computing (DSDI). Census National Agriculture, Abidjan, $57 \mathrm{p}$.

[12] Orou, K.R. (2017) Influence of the Use of Agricultural Inputs on the Quality of Water Resources and Associated Health Impacts: Case of the Department of Agboville (South-East of Côte d'Ivoire). PhD Felix Houphouët Boigny University, Abidjan.

[13] Perraud, A. and De La Souchere (1970) Map of the Soil Sketch of the CI at 1/500,000.

[14] Anoh, K.A. (2014) Contribution of a GIS and the SWAT Agro-Hydrological Model in the Sustainable Management of Water Resources in the Catchment Area of Lake Taabo (Center of Côte d'Ivoire). PhD Félix Houphouët Boigny University, Abidjan. 
[15] Deh, K.S., Kouame, K.J., Eba, A.L., Edoukou, D.J., Kpan, A. and Jourda, J.P. (2017) Contribution of Geographic Information Systems in Protection Zones Delineation around a Surface Water Resource in Adzope Region (Southeast of Côte d'Ivoire). Journal of Environmental Protection, 8, 1652-1673. https://doi.org/10.4236/jep.2017.813102

[16] Ake, G.E., Eba, A.E.L., Assi, J.J., Kouadio, B.H. and Biemi, J. (2019) Contribution of GIS to the Delimitation of the Protection Perimeters around the Sodeci Water Intake in Aboisso, South-East of Côte d'Ivoire. Afrique Sciences, 15, 234-252.

[17] Eba, A.E., Kouame, K.J., Deh, S.K., Anoh, K.A., Balliet, R., Toure, M. and Jourda, J.P. (2016) Assessment of the Vulnerability to Pollution of Surface Water Intended for the Supply of Drinking Water to a Metropolitan Area. Case of the Aghein Lagoon in Abidjan, (South of Côte d'Ivoire). European Scientific Journal, 12, 306-326.

[18] Soro, N. (1987) Contribution to the Geological and Hydrogeological Study of the South-East of Côte d'Ivoire: Watershed of the Mé. Doctoral Thesis 3rd Cycle, University of Grenoble 1, Institute Dolomieu, Dolomieu, 239 p.

[19] Saaty, T.L. (1977) A Scaling Method for Priorities in Hierachical Structures. Journal of Mathematical Psychology, 15, 234-281. https://doi.org/10.1016/0022-2496(77)90033-5

[20] El Morjani (2002) Design of a Spatial Reference Information System for Environmental Management; Application to the Selection of Potential Storage Sites for Household and Industrial Waste in the Semi-Arid Region (Sousse, Morocco). $\mathrm{PhD}$ of the University of Geneva, Earth and Environment, Vol. XLII, Geneva.

[21] Roy, B. (1985) Multi-Criteria Decision Support Methodology. Économica, 22, 423 p.

[22] Jourda, J.P., Kouassi, K.J., Adja, M.G., Deh, S.K., Anani, A.T., Effini, A.T. and Biemi, J. (2007) Assessment of the Degree of Protection of Groundwater: Vulnerability to Pollution of the Bonoua Aquifer (South-East of Côte d'Ivoire) by the Drastic Method. Francophone Conference Proceedings, Versailles, 10-11 October 2007, 18 p.

[23] Carre, J. (2005) Protection of Surface Water Intakes Intended for Drinking Water Supply. TSM numéro 4, 27-34.

[24] Anoh, K.A., Jourda, J.P., Kouame, K.J., Koua, T.J.-J., Eba, A.E. and Lazar, G. (2012) Demarcation of Protection Perimeters for Surface Waters of Taabo (Côte d'Ivoire) Watershed Using GIS and Multicriteria Analysis. Environmental Engineering and Management Journal, 11, 2123-2131. https://doi.org/10.30638/eemj.2012.264

[25] Macary, F., Balestrat, M., Puech, C. and Saudubray, F. (2006) Method for Estimating a Potential Spatialized Risk of Contamination of Surface Water by Agricultural Inputs at Different Spatial Scales. Application on the Slopes of Gascogne. $20 \mathrm{p}$.

[26] Schoen, R., Ricard, J. and Codvelle, A. (2001) Mapping of the Hazard of Pollution of Surface and Groundwater by Phytosanitary Substances in the Midi-Pyrénées Region, Vulnerability of Groundwater, Rapport BRGM/RP-51337-FR. 32 p.

[27] Kpan, G.H. (2016) Contribution of Geographic Information Systems (GIS) in Determining the Protection Perimeters of the Adzope Reservoir. Master Memory, University of Felix Houphouët Boigny, Abidjan.

[28] Bibeau, R. and Breune, I. (2009) Municipal Regulatory Initiatives for Environmental Protection in Agricultural Areas in Quebec: State of Play. Ed. Agriculture and Agrifood Canada, $69 \mathrm{p}$.

[29] MEEB (2010) Benin Ministry of Energy and Water. Methodological Guide for the Use of Municipalities. $10 \mathrm{p}$.

[30] ONEP-GTZ (1995) Study for the Request for the Installation of Protective Perime- 
ters for the Sidi Mohamed Ben Abdellah Dam on Oued Bou Regreg. National Office for Drinking Water and Gesellschaft fur Technische Zusammenarbeit, National Office of Drinking Water of Morocco, Scientific Report, 175 p. 